\title{
Female Cadaveric Study of Neurovascular Pedicle in Latissimus Dorsi Muscle Flap
}

\author{
Latha V. Prabhu, Mangala M. Pai, Y. Lakshmisha Rao, B. V. Murlimanju, R. Vadgaonkar \\ Department of Anatomy, Kasturba Medical College, Manipal Academy of Higher Education, Manipal, Karnataka, \\ India
}

\author{
CORRESPONDING AUTHOR: \\ Bukkambudhi Virupakshamurthy \\ Murlimanju \\ Department of Anatomy \\ Kasturba Medical College \\ Manipal-Mangalore 575004 \\ Karnataka, India \\ E-mail: flutemist@gmail.com
}

DOI:

10.32098/mltj.04.2020.10

LEVEL OF EVIDENCE: 4

\begin{abstract}
SUMMARY
Background. The goal of this investigation was to analyse the branching pattern of the arterial supply and innervation of Latissimus Dorsi (LD). The aim was also to determine the distance of origin of its neurovascular pedicle from the inferior scapular angle.

Methods. The present study included 9 adult female embalmed cadavers, which were available in the department of anatomy. Neurovascular pedicle of the latissimus dorsi was studied over the right and left sides $(\mathrm{n}=18)$. The long thoracic artery origin was also observed. The distance of the neurovascular pedicle from the scapular inferior angle was measured by using a digital Vernier calliper.

Results. It was observed that, in $44.4 \%$ cases, type 1a pattern of the thoracodorsal artery was observed. Type A pattern of thoracodorsal nerve was observed in $55.5 \%$ cases. It was observed that the thoracodorsal nerve was laterally related to the artery to LD in $94.5 \%$ cases. The distance of origin of neurovascular pedicle of LD from the inferior scapular angle was $60.8 \pm 6.2 \mathrm{~mm}$ over the right side and the same measurement was $59.8 \pm 6.4 \mathrm{~mm}$ over the left side. The comparison of this data didn't show statistical significance (Paired t Test, $\mathrm{p}=0.49$ ). Conclusions. It was observed that the arterial branching pattern of the LD muscle was extremely variable. The findings will assist the plastic surgery during the breast reconstruction procedure.
\end{abstract}

\section{KEY WORDS}

Breast reconstruction; latissimus dorsi; pedicled flap; surgical flap; breast tumors; cosmetic surgery.

\section{BACKGROUND}

Latissimus Dorsi (LD) is a back muscle, which is sometimes known as "climbers muscle". The LD is used in flap surgeries by the plastic surgeons particularly during the breast reconstruction. The LD flap is preferred in mammary gland reconstruction because of its lesser perioperative and long term postoperative morbidity (1). LD is innervated by thoraco dorsal nerve and its arterial supply is by the thoraco dorsal artery. In the posterior wall of axilla, the subscapular artery is inferiorly related to the LD and gives a branch, the circumflex scapular artery. After this branch, the thoracodorsal artery is the continuation of subscapular artery. The long thoracic artery supplies the serratus anterior muscle, which is a branch of thoracodorsal artery (2). Thoracodorsal artery provides two branches inside the LD, descending and transverse branches (3). LD also gets nourishment by the lumbar and posterior intercostal arteries. Thoracodorsal artery has a wider diameter and with least anatomical variations, becomes a highly reliable source $(3,4)$.

A pedicle of size, 50-100 millimetres can be safely harvested from the subscapular system. Since the arteries branches inside the latissimus dorsi muscle, the muscle can be cut longitudinally and bilobed flap can be harvested. These pedicled flaps could be used to cover the posterior defects (2). LD is also used for the reconstruction of face, scalp and cranium defects, pedicle transplant rotator cuff repairs, tendon graft surgeries and reconstruction flap for the extremities (2). LD flap is used to cover the extremely larger and deeper wounds. Because of the larger size of the LD, there are no postharvest motor deficits (2). The anatomical reports about the variations in the arterial supply branching pattern and innervation are scarce in the scientific literature. This was the stimulus to perform the present study in the female cadaveric specimens of south Indian origin. The goal 
of the present investigation was to analyse the branching pattern of the arterial tree and innervation of LD muscle. The morphology of various branching patterns was noted and analysed. The aim was also to determine the distance of origin of its neurovascular pedicle from the inferior scapular angle.

\section{MATERIALS AND METHODS}

The present study included 9 adult female embalmed cadavers, which were available in the department of anatomy. The neurovascular pedicle of $\mathrm{LD}$ was studied over the right and left sides $(n=18)$. The sample size was calculated after consultation with the statistician. This study has been approved by the ethics committee of our institution. Male cadavers were not included because this study was aimed to help the breast construction procedures. This was a posterior exposure just like the surgical approach and the muscular flap was elevated from the origin of LD. This is not routinely done in regular anatomical dissections, where we perform it from the anterior approach.

The incision was put at T3 level both horizontally and vertically. After reflecting the superficial and deep fascia, the LD muscle was defined. The part of LD below the scapular inferior angle was released. The attachments of $\mathrm{LD}$ at the spine in the back was also released. The dissection was continued below the $\mathrm{LD}$ toward the axillary region. The arteries to $\mathrm{LD}$ and serratus anterior became obvious as we approached towards the axilla. Once the flap was raised from proximal to distal, the neurovascular pedicle was dissected near the posterior wall of axilla. The distance of the pedicle near the lateral border of scapula from the scapular inferior angle was noted as this may give an idea to the operating surgeon where exactly he or she can locate the pedicle. This measurement was performed by using a digital Vernier calliper. The upper extremity of the cadavers was abducted to $90^{\circ}$ position with respect to the thorax, both during the dissection procedure and while performing the measurement.

The branching pattern of the nerve to LD muscle (thoracodorsal nerve) and arterial tree of LD were analysed. The origin of artery to serratus anterior (long thoracic artery) was also studied. The observations were analysed and tabulated. The branching pattern of the artery to $\mathrm{LD}$, was classified based on its branching pattern into types $1 \mathrm{a}, 1 \mathrm{~b}, 2 \mathrm{a}, 2 \mathrm{~b}$, $2 \mathrm{c}, 3 \mathrm{a}, 3 \mathrm{~b}$ and $3 \mathrm{c}$, which are as below (figure 1):

Type 1a: artery to LD ( 4 in the picture) was branching from SCA and later divided into two branches $(4 \mathrm{a}$ and $4 \mathrm{~b}$ in the pictures).

Type 1b: artery to LD ( 4 in the picture) was branching from SCA and later divided into three branches $(4 a, 4 b$ and $4 c$ in the pictures).
Type 2a: artery to $\operatorname{LD}$ ( 4 in the picture) was branching from SCA and later divided into two branches $(4 \mathrm{a}$ and $4 \mathrm{~b}$ in the pictures). These two branches again branched into two more branches each (4a and $4 \mathrm{~b}$ again branched into $4 \mathrm{a} 1$, $4 \mathrm{a} 2,4 \mathrm{~b} 1$ and $4 \mathrm{~b} 2$ branches).

Type $2 \mathrm{~b}$ : artery to LD ( 4 in the picture) was branching from SCA and later divided into two branches $(4 \mathrm{a}$ and $4 \mathrm{~b}$ in the pictures). The first branch $4 \mathrm{a}$, again branched into $4 \mathrm{a} 1$ and $4 \mathrm{a} 2$ branches. The second branch $4 \mathrm{~b}$, there was no further branching.

Type 2c: artery to LD ( 4 in the picture) was branching from SCA and later divided into two branches $(4 \mathrm{a}$ and $4 \mathrm{~b}$ in the pictures). The second branch $4 \mathrm{~b}$, again branched into $4 \mathrm{~b} 1$ and $4 \mathrm{~b} 2$ branches. The first branch $4 \mathrm{a}$, there was no further branching.

Type 3a: there was no single trunk (4), instead there were two arteries to LD directly arising from the SCA ( $4 \mathrm{a}$ and $4 \mathrm{~b}$ ). Type 3b: there was no single trunk (4), instead there were three arteries to LD directly arising from the SCA (4a, $4 \mathrm{~b}$ and $4 \mathrm{c})$.

Type $3 \mathrm{c}$ : there was no single trunk (4), instead there were two arteries to LD directly arising from the SCA (4a and $4 \mathrm{~b})$. These two branches again branched into two more branches each (4a and $4 \mathrm{~b}$ again branched into $4 \mathrm{a} 1,4 \mathrm{a} 2,4 \mathrm{~b} 1$ and $4 \mathrm{~b} 2$ branches).

The branching pattern of the thoracodorsal nerve was classified based on its level of branching a type A, type B and type $\mathrm{C}$, which are as below (figure $\mathbf{1}$ ):

Type A: thoracodorsal nerve dividing at the level of origin of circumflex scapular artery.

Type B: thoracodorsal nerve dividing above the level of origin of circumflex scapular artery.

Type C: thoracodorsal nerve dividing below the level of origin of circumflex scapular artery.

The dimension measured was analyzed statistically by using "EZR software, version 1.38, 2019". The statistical analysis of right and left side dimensions were done by using the paired t Test. The comparison was considered as significant statistically only if the p value is smaller than 0.05 .

We state that the present anatomical investigation was performed as per the international ethical standards, which are required by the international scientific indexed journal as per the opinion of Padulo et al. (5).

\section{RESULTS}

In all the cadavers, artery to LD was branching from the subscapular artery. But the branching was extremely variable after its origin from the subscapular artery. The various morphological branching patterns of the vascular pedicles are represented along with their frequency in figures 2-8. 


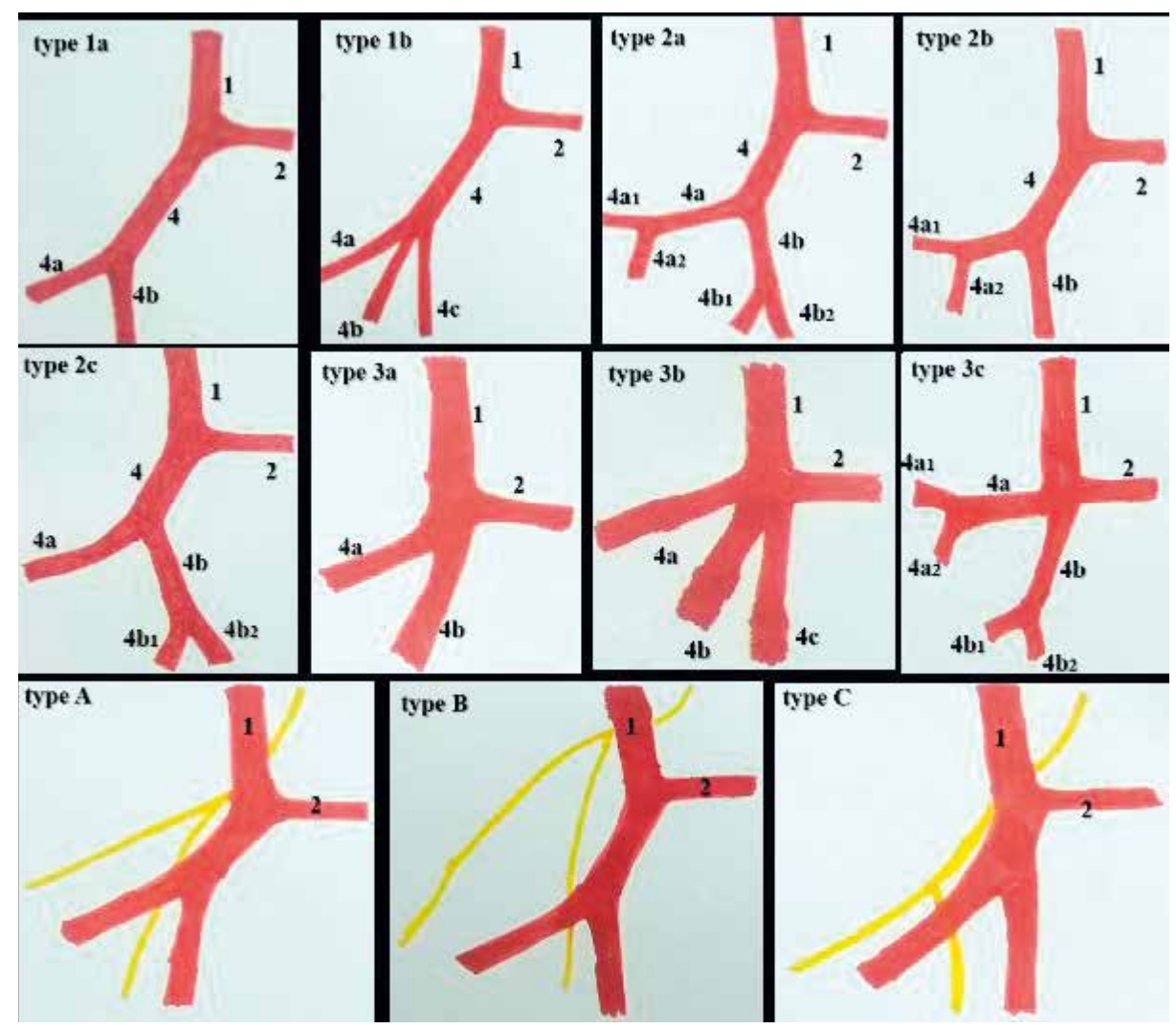

Figure 1. Schematic diagrams representing the various branching pattern of the artery to $L D$ (type $1 a$, type $1 b$, type $2 a$, type $2 b$, type $2 c$, type $3 a$, type $3 b$ and type $3 c$ ) and thoracodorsal nerve (type $A$, type $B$ and type $C$ ), which are observed in this study.

Their frequency over the right and left sides are represented in table I. It was observed that, in $44.4 \%$ cases, type $1 \mathrm{a}$ (figure 2) pattern was observed, this was the most common pattern. In this pattern, artery to $\mathrm{LD}$ was branching from the SCA and later divided into two branches. It was also found that the branching pattern is not the same over the right and left side $(77.8 \%$ cases) of the same person. The branching pattern was same bilaterally in only $22.2 \%$ cases. It was observed that in 17 cases $(94.4 \%)$, the artery to serratus anterior (long thoracic artery) was branching from the circumflex scapular artery. However, in 1 case $(5.6 \%)$, the long thoracic artery was branching from the artery to LD.

Table II represents the frequency of various morphological types of branching pattern of the thoracodorsal nerve. The type A variety is seen in figure 4, type B in figure 8 and type $\mathrm{C}$ in figure $\mathbf{6}$, respectively. The branching pattern of thoracodorsal nerve was similar in 5 cadavers ( $55.5 \%$ cases) and it was different in $44.5 \%$ cases. It was observed that the thoracodorsal nerve was laterally related to the artery
Table I. Various morphological patterns of vascular pedicles of $L D$ and their frequency over right $(n=9)$ and left $(n=9)$ sides.

\begin{tabular}{lll}
\hline Branching pattern & Right side & Left side \\
\hline Type 1a & $4(22.2 \%)$ & $4(22.2 \%)$ \\
\hline Type $1 \mathrm{~b}$ & $2(11.2 \%)$ & $1(5.5 \%)$ \\
\hline Type 2a & NUL $(0 \%)$ & NUL $(0 \%)$ \\
\hline Type 2b & $1(5.5 \%)$ & $1(5.5 \%)$ \\
\hline Type 2c & NUL $(0 \%)$ & $1(5.5 \%)$ \\
\hline Type 3a & $1(5.5 \%)$ & NUL $(0 \%)$ \\
\hline Type 3b & NUL $(0 \%)$ & $2(11.2 \%)$ \\
\hline Type 3c & $1(5.5 \%)$ & NUL $(0 \%)$ \\
\hline
\end{tabular}




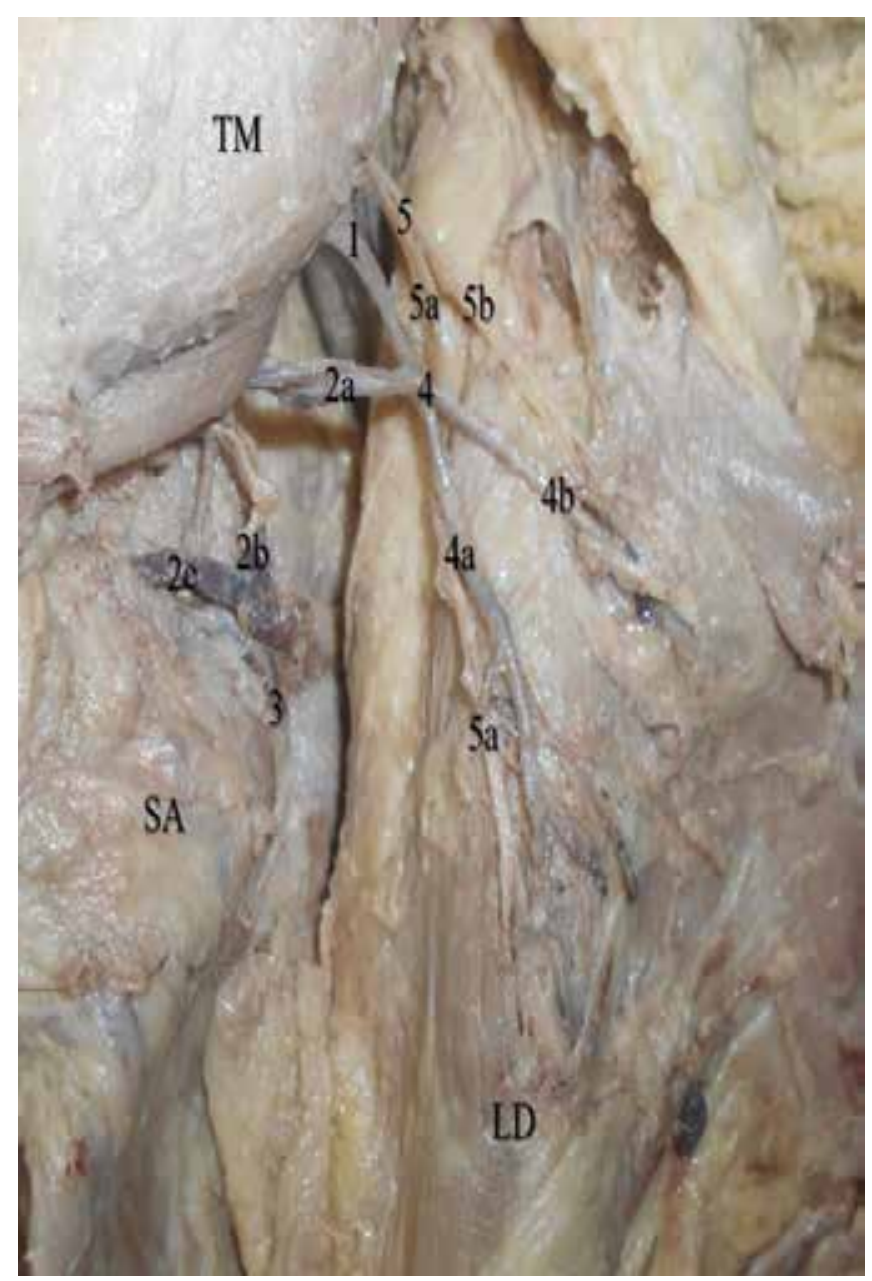

Figure 2. Latissimus dorsi muscle having type 1a branching pattern of the vascular pedicle (8 cases, $44.4 \%)$.

to $\mathrm{LD}(94.5 \%$ cases), except in only one side $(5.5 \%)$, this was found on the medial side of the artery. The distance of the origin of neurovascular pedicle of the LD from the inferior angle of scapula was $60.8 \pm 6.2 \mathrm{~mm}$ over the right side and the same measurement was $59.8 \pm 6.4 \mathrm{~mm}$ over the left side. The measurements of all the cadavers over the right and left sides with respect to the distance of pedicle is given in table III. The comparison of this data didn't show statistical significance (paired t Test, $\mathrm{p}=0.49$ ).

\section{DISCUSSION}

The prevalence rate of carcinoma of breast has increased in the recent years. It is fortunate that there are good treatment modalities available like surgery, chemotherapy and radiotherapy. Radical mastectomy is the best surgical proce-
Table II. Morphological patterns of the thoracodorsal nerve and their frequency $(n=18)$.

\begin{tabular}{ll}
\hline Morphological pattern & Frequency \\
\hline Type A & $10(55.5 \%)$ \\
\hline Type B & $5(27.8 \%)$ \\
\hline Type C & $3(16.7 \%)$ \\
\hline
\end{tabular}

Table III. Distance of the neurovascular pedicle from the inferior angle of scapula $(n=18)$.

\begin{tabular}{lll}
\hline Cadaver number & Right side & Left side \\
\hline 1 & $61 \mathrm{~mm}$ & $61 \mathrm{~mm}$ \\
\hline 2 & $56 \mathrm{~mm}$ & $56 \mathrm{~mm}$ \\
\hline 3 & $57 \mathrm{~mm}$ & $51 \mathrm{~mm}$ \\
\hline 4 & $72 \mathrm{~mm}$ & $66 \mathrm{~mm}$ \\
\hline 5 & $65 \mathrm{~mm}$ & $65 \mathrm{~mm}$ \\
\hline 6 & $63 \mathrm{~mm}$ & $61 \mathrm{~mm}$ \\
\hline 7 & $50 \mathrm{~mm}$ & $55 \mathrm{~mm}$ \\
\hline 8 & $66 \mathrm{~mm}$ & $71 \mathrm{~mm}$ \\
\hline 9 & $57 \mathrm{~mm}$ & $52 \mathrm{~mm}$ \\
\hline
\end{tabular}

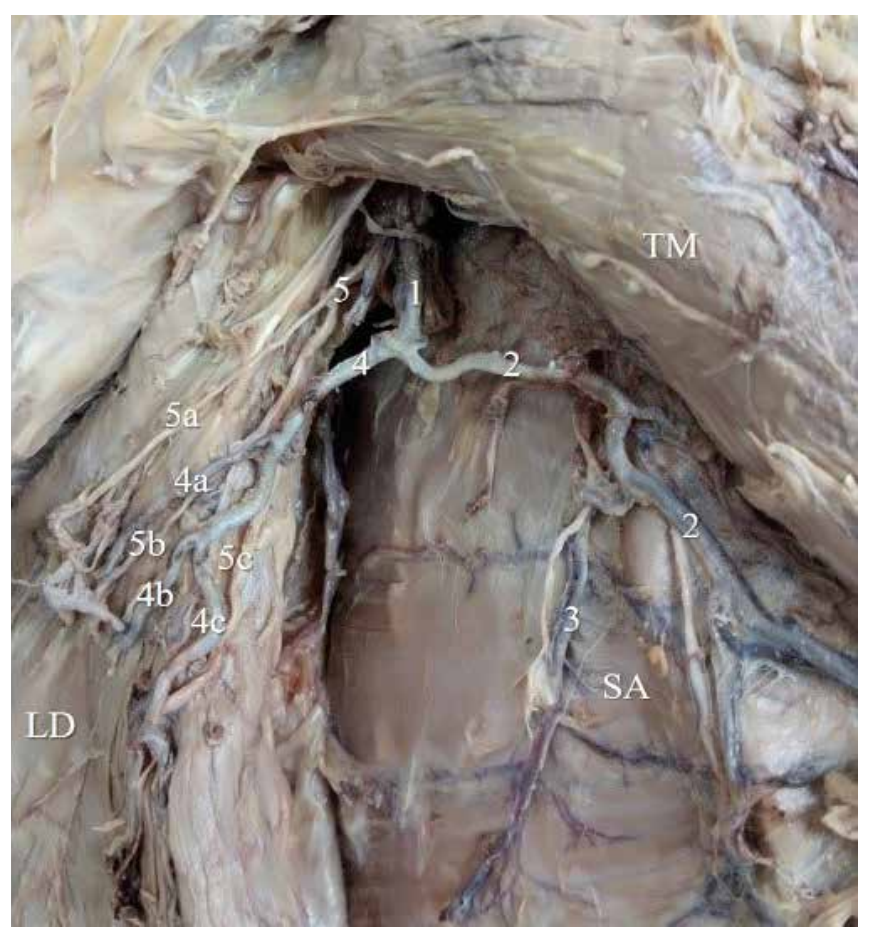

Figure 3. Latissimus dorsi muscle having type $1 \mathrm{~b}$ branching pattern of the vascular pedicle (3 cases, 16.7\%).

Muscles, Ligaments and Tendons Journal 2020;10 (4) 


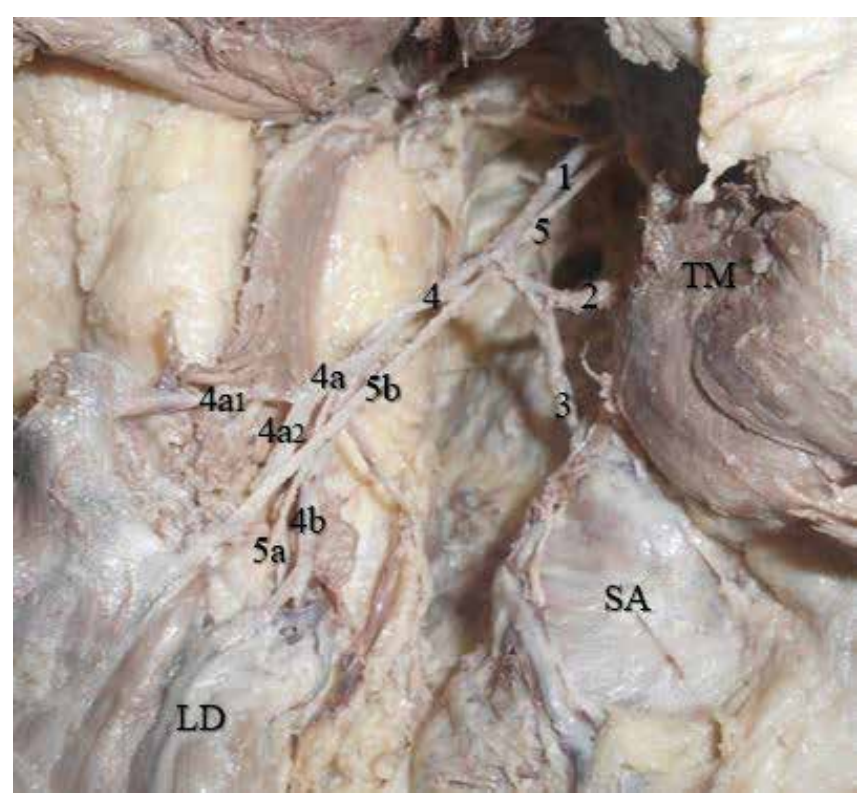

Figure 4. Latissimus dorsi muscle having type $2 \mathrm{~b}$ branching pattern of the vascular pedicle (2 cases, $11.2 \%$ ). The thoracodorsal nerve branching pattern in this picture is type $A(n=10$, $55.5 \%$ cases).

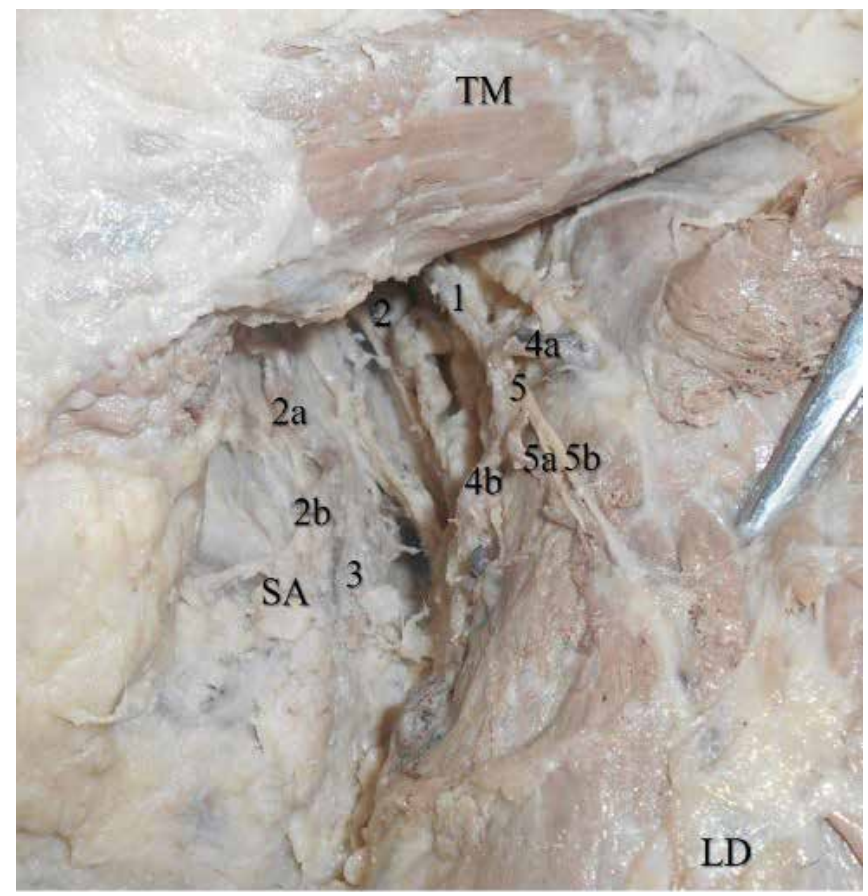

Figure 6. Latissimus dorsi muscle having type 3a branching pattern of the vascular pedicle (1 case, 5.5\%). The thoracodorsal nerve branching pattern in this picture is type $C(n=3$, $16.7 \%$ cases).

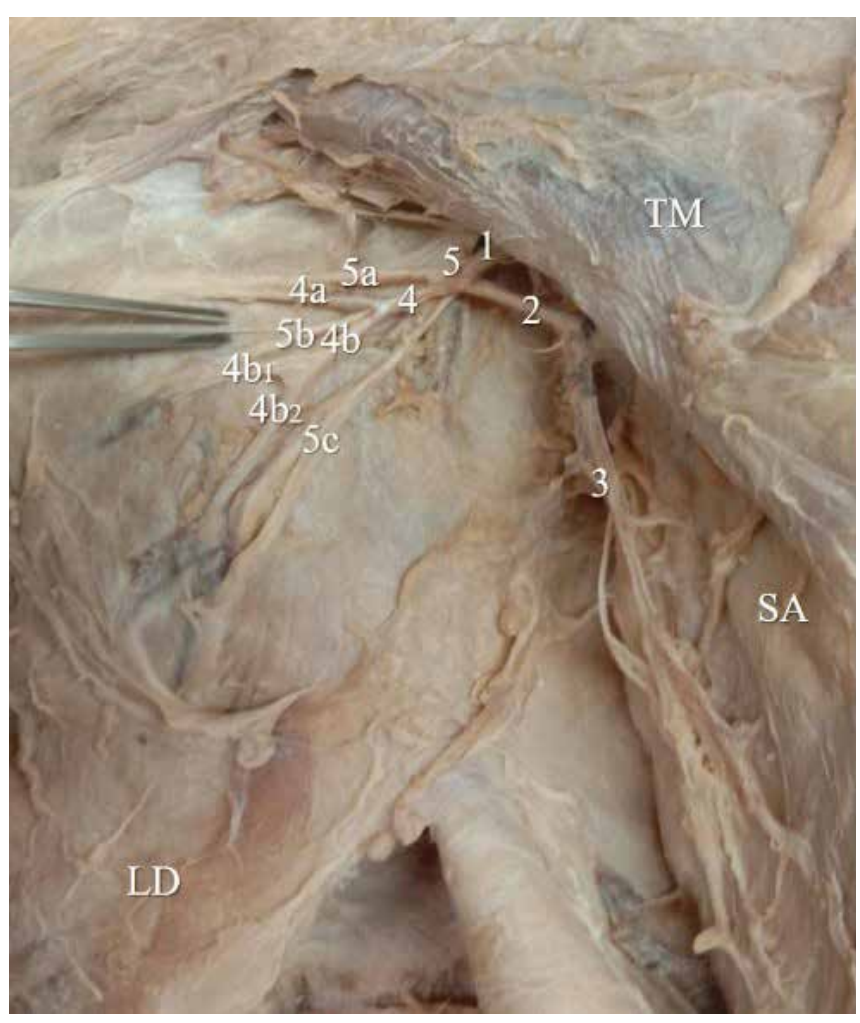

Figure 5. Latissimus dorsi muscle having type 2c branching pattern of the vascular pedicle (1 case, $5.5 \%$ ).

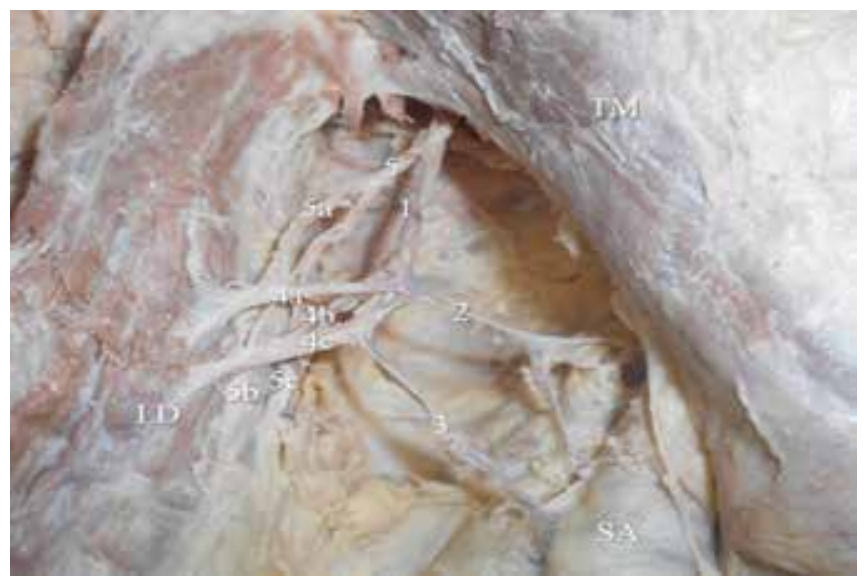

Figure 7. Latissimus dorsi muscle having type $3 \mathrm{~b}$ branching pattern of the vascular pedicle (2 cases, $11.2 \%$ ). 


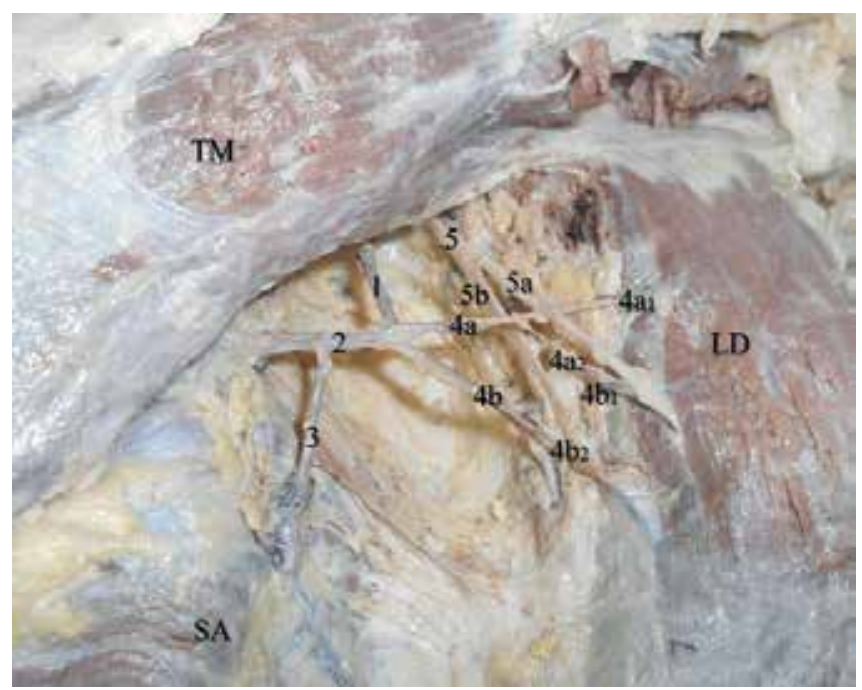

Figure 8. Latissimus dorsi muscle having type $3 c(n=1,5.5 \%$ cases) branching pattern of the vascular pedicle. The thoracodorsal nerve branching pattern in this case is type $B(n=5$, $27.8 \%$ cases).

dure, which is followed by the breast reconstruction. This is performed by the plastic surgeon for the cosmetic purpose. The graft can be harvested from the same patient during the mastectomy procedure. The LD muscle flap technique was described in 1906 by Iginio Tansini, but it became popular only in 1970s for the breast reconstruction (6). William Halsted included LD flap during the radical mastectomy (3) and Schneider et al. (7) reported the use of LDF in implantbased mammary gland reconstruction. LD flap maintained the shape and function of the silicone implant by forming the muscle coverage. Bostwick et al. (8) made a skin island over the LD to replace the skin loss during the post mastectomy breast reconstruction. Papp and McCraw (9) found a LDF which is de-epithelialized and it provided the volume replacement. The muscle flap with its nerve intact can be used for the reconstruction of the paralysed face and in Poland syndrome. With the nerve inside the flap, the muscle function is maintained (10). LD with its nerve and artery can be used as a flap to reconstruct the paralysed deltoid and triceps muscles (11). The osteo-musculo-cutaneous flaps with the LD can be used to reconstruct the mandible (12). LD tendon transfer is among the best treatment options for the massive posterior-superior rotator cuff tears, especially in the younger patients (13). The LD is best suited for the transfer procedures, because of its strength, vascularization, and larger surface area. These things are essential to the successful healing (14). In the arthroscopic surgeries performed with the lateral decubitus position for the rota- tor cuff tears, the traction is given to the LD muscle. This requires the topographical location of the thoracodorsal nerve and knowledge about its variability. It was described that the LD pedicle with supply by the long thoracic artery and nerve can be mobilized without tension up to $80 \mathrm{~mm}$ (14).

During the surgical mobilization of the LD muscle, all the perforating arteries from the posterior intercostal and lumbar will be divided and the only arterial supply from the thoracodorsal artery remains (15). Hence it was essential to study the branching pattern of thoracodorsal artery inside the LD. The LD is supplied by a single motor nerve, thoracodorsal nerve which divides after entering the LD (16). The nerve passes posterior to the axillary artery, joins the vascular pedicle, and enters the LD along with the artery. The artery and nerve to LD bifurcate after their entry into the LD muscle. It was reported that, based on this branching pattern, one can use one or both units of the muscle for the transfer as required by the individual case $(17,18)$.

In the literature, there are few clinical reports available, there are not enough anatomical studies which explain the neurovascular distribution of the LD. Anatomical reports are very much essential as they serve as the basic in the medical research. The present study has examined the detailed distribution of thoracodorsal nerve and branching of the thoracodorsal artery in female cadavers. This type of study is not reported earlier from the female cadavers of the south Indian population. The data of the present study were compared with the few available previous reports. Bartlett et al (17) observed the subscapular-thoracodorsal artery vascular pedicles of $11 \mathrm{~cm}$ mean length. The long thoracic artery branches from the thoracodorsal artery were observed previously by Bartlett et al. (17). In the present study, this pattern of origin of long thoracic artery was observed only in $5.6 \%$ cases. It was observed that, in $94.4 \%$ of our cases the long thoracic artery was branching from the circumflex scapular artery. Bartlett et al. (17) reported that the neurovascular structures in the latissimus dorsi were bifurcated into superior and lateral intramuscular bundles in $86 \%$ of their specimens. This pattern is labelled as type $1 \mathrm{a}$ in this study and it was observed in only $44.4 \%$ cases. Kwon et al. (10) opined that the thoracodorsal nerve always branched before the thoracodorsal artery, and the distance from the first branch of the nerve to the first branch of the artery was $20.4 \pm 8.9 \mathrm{~mm}$. In the present study, the thoracodorsal nerve branching before the artery was labelled as type $B$ and observed in $27.8 \%$ cases.

It is described that the surgeon should have adequate knowledge about the arterial tree and divisions of thoracodorsal nerve of the LD muscle. This LD muscle is commonly used in the pedicle grafts in the plastic surgical practice 
following the mastectomy. It was observed that the arterial branching pattern of the LD muscle was extremely variable. The finding of the present study is useful to the reconstructive surgery, since the distance of origin of neurovascular pedicle of $\mathrm{LD}$ from the inferior scapular angle was constant. There was no statistically significant difference between the right versus left sides, in all the female embalmed cadavers. So, the data of the present study can be used as anatomical guide for the surgical dissection with respect to the distance of the neurovascular pedicle from the inferior angle of scapula.

However, this study has certain limitations like the sample size, which was very small. We could be able to dissect only 18 muscles, from the 9 female cadavers. The study can be more accurate with a large sample size of female cadavers. This study also focused on evidence gathered using cadavers from Indian region, the results may be influenced by the ethnic predispositions in the Indian sample. Further studies, based on larger and ethnically diverse samples, may determine whether outcomes vary for different ethnic groups. The high variability in the pattern of the vascular tree between the two sides of the same subject has modest

\section{REFERENCES}

1. Sood R, Easow JM, Konopka G, Panthaki ZJ. Latissimus dorsi flap in breast reconstruction: recent innovations in the workhorse flap. Cancer Control 2018;25:1073274817744638.

2. Bhatt CR, Prajapati B, Patil DS, Patel VD, Singh BG, Mehta CD. Variation in the insertion of the latissimus dorsi \& its clinical importance. J Orthop 2013;10:25-28.

3. Spear SL, Clemens MW. Latissimus dorsi flap breast reconstruction. In: Neligan PC, Grotting JC (eds). Plastic Surgery. 3rd ed. Philadelphia: Saunders (Elsevier), 2012;pp. 370-392.

4. Mathes SJ, Nahai F. Classification of the vascular anatomy of muscles: experimental and clinical correlation. Plast Reconstr Surg 1981;67:177-187.

5. Padulo J, Oliva F, Frizziero A, Maffulli N. Muscles, Ligaments and Tendons Journal - Basic principles and recommendations in clinical and field Science Research: 2016 Update. MLTJ 2016;6:1-5.

6. Maxwell GP. Iginio Tansini and the origin of the latissimus dorsi musculocutaneous flap. Plast Reconstr Surg 1980;65:686-692.

7. Schneider WJ, Hill HL Jr, Brown RG. Latissimus dorsi myocutaneous flap for breast reconstruction. Br J Plast Surg 1977;30:277-281.

8. Bostwick J III, Vasconez LO, Jurkiewicz MJ. Breast reconstruction after a radical mastectomy. Plast Reconstr Surg 1978;61:682-693.

9. Papp C, McCraw JB. Autogenous latissimus breast reconstruction. Clin Plast Surg 1998;25:261-266. clinical relevance. The surgeon, in fact, operates just one out of the two sides. But the remarkable variability of the vascular and nervous pattern, on the other hand, has practical relevance to the surgeon. The upper extremities were positioned at $90^{\circ}$ abduction and this can affect the distance of the lower angle of the scapula to the pedicle. But the patients can be positioned with $90^{\circ}$ abduction of arm in the surgical setting as well.

\section{CONCLUSIONS}

The present study has provided information about the various branching pattern of the arterial supply and innervation of the LD muscle. This study was performed exclusively by using the female cadavers from the sample south Indian population. The data of the present study may help the operating surgeons while harvesting the neurovascular pedicle flaps during the breast reconstruction procedure.

\section{CONFLICT OF INTERESTS}

The authors declare that they have no conflict of interests.
10. Kwon ST, Chang H, Oh M. Anatomic basis of interfascicular nerve splitting of innervated partial latissimus dorsi muscle flap. J Plast Reconstr Aesthet Surg 2011;64:e109-e114.

11. Du Toit GT, Levy SJ. Transposition of latissimus dorsi for paralysis of triceps brachii. Report of a case. J Bone Joint Surg Br 1967;49:135-137.

12. Kim PD, Blackwell KE. Latissimus-serratus-rib free flap for oromandibular and maxillary reconstruction. Arch Otolaryngol Head Neck Surg 2007;133:791-795.

13. Oliva F, Piccirilli E, Bossa M, et al. I.S.Mu.L.T - Rotator Cuff Tears Guidelines. MLTJ 2016;5:227-263.

14. De Cupis V, De Cupis M. Massive cuff tears treated with arthroscopically assisted latissimus dorsi transfer. Surgical technique. MLTJ 2012;2:149-153.

15. Salmons S. Invited review: avoiding ischaemic damage in latissimus dorsi muscles redeployed as functional grafts. Basic Appl Myol 2003;13:71-81.

16. Taylor GI, Gianoutsos MP, Morris SF. The neurovascular territories of the skin and muscles: anatomical study and clinical implications. Plast Reconst Surg 1994;94:1-36.

17. Bartlett SP, May JW Jr, Yaremchuk MJ. The latissimus dorsi muscle: a fresh cadaver study of the primary neurovascular pedicle. Plast Reconstr Surg 1981;67:631-636.

18. Tobin GR, Schusterman M, Peterson GH, Nichols G, Bland KI. The intramuscular neurovascular anatomy of the latissimus dorsi muscle; the basis for splitting the flap. Plast Reconstr Surg 1981;67:637-641. 